Journal of Mathematics and Statistics 7 (3): 187-197, 2011

ISSN 1549-3644

(C) 2011 Science Publications

\title{
Establishing an Adaptive Production-Procurement System with Markov Chain Approach Associated with 3C Theory
}

\author{
Chun-Ta Lin \\ Department of Information Management, \\ Yu-Da University Miao-Li, ROC, Taiwan
}

\begin{abstract}
Problem statement: In this study, we classify the imperfect situations that the unreliability of production and the defective products might be incurred from production process into eight independently recurrent categories. Approach: With the property of recurrence of Markov chain, the limiting probability of each imperfect production category can be calculated through the transition probabilities matrix generated from these imperfect production categories. Results: The 3C Theory has been applied based on a certain group of products to integrate the relationship between order model and resource requirement plans. Therefore, an adaptive (s, Q) production system with Markov Chain Approach associated with (R, s, S) procurement system based on 3C Theory has been proposed to smooth supply disruptions incurred from imperfect production. Conclusion/Recommendations: We have demonstrated that the candidate solutions identified by the proposed method are not only superior to traditional EPQ model solutions, but also result in significantly smaller cost flow variability.
\end{abstract}

Key words: 3C theory, Markov Chain approach, supply disruptions, Material Requirement Planning (MRP), production process, inventory policy, Bill Of Material (BOM), Net Present Value (NPV), economic, supply chain

\section{INTRODUCTION}

Every supply chain faces disruptions of various sorts. Recent literatures and articles in the academy and popular press have pointed out the vulnerability of today's supply chains to disruptions and the need for a systematic analysis of supply chain vulnerability, security and resiliency (Ross, 1997). In the early 1990s, researchers began to embed supply disruptions into classical inventory models, assuming that a firm's supplier might experience a disruption when the firm wished to place an order (Parlar, 1997; Yano and Lee, 1995). Examples include models based on the Economic Order Quantity (EOQ) model (Berk and Arreola-Risa, 1994; Parlar and Berkin, 1991), the (R, Q) model (Gupta, 1996; Parlar, 1997) and the (s, S) model (Arreola-Risa and DeCroix, 1998). All of these models are generally less tractable than their reliable supply counterparts, although they can still be solved easily using relatively simple algorithms.

More recent literature has addressed higher level, strategic decisions made by firms in the face of disruptions. For example, Tomlin (2006) explores strategies for coping with disruptions, including inventory, dual sourcing and acceptance (i.e., simply accepting the risk of disruption and not protecting against it) and shows that the optimal strategy changes as the disruption characteristics change (e.g., disruptions become longer or more frequent). Tomlin and Snyder (2006) examine how strategies change when a firm has advance warning of an impending disruption. Lewis et al. (2005) consider the effects of border closures on lead times and costs. Chopra et al. (2005; 2007) evaluate the error that results from "bundling" disruptions and yield uncertainty when making inventory decisions. Related research also can be found in (Cachon and Fisher, 2000; Olugu and Wong, 2009; Lin and Chen, 2009).

The supply and demand characteristics are a way to look at uncertainties of a supply chain. Yet, there may be supply chains where the explicit distinction of a third type of uncertainty mentioned in (Lee, 2002), namely the process uncertainty, may be important. This third type of uncertainty relates to the production of the product itself, that is, the supply chain of production and procurement within a firm, which relates to the supply side and the demand side. Yet, it is intrinsic to the production process itself. If the process uncertainty 


\section{J. Math. \& Stat., 7 (3): 187-197, 2011}

plays an important role in the supply chain, explicit distinction may be advantageous.

The first treatment of supply disruptions in the literature appears to be made by Meyer et al. (1979), who consider a production facility subject to stochastic disruptions and repairs. Items produced by the facility are stored in a capacitated buffer that sees constant, deterministic demand. Their model is descriptive rather than prescriptive, characterizing the stockout percentage for a given inventory policy rather than finding the optimal policy. Kimemia and Gershwin (1983) considered machine unreliability, maintenance and downtime in the flexible manufacturing system to control the production system to meet the specification and develop a calculation model to solve control problems of the inventory. Related research also can be found in (Kimemia and Gershwin, 1983; Lee, 1992; Lee, and Yano, 1988; Liu and Cao, 1997; Liu and Yang, 1996; Usman and Kontagora, 2010).

The 3C approach developed by Lucent (FernandezRanada et al., 1999) in its Spanish Tres Cantos plant links sales planning seamlessly to component suppliers using a collaboration process based on ranking maximum usage rates of individual components (Holmstrom et al., 2002). 3C Theory is the basic theory for realizing global supply chain management and designed to plan and realize global resource project. In the past, we even do not know the disruption between activity processes of order model, purchase, production and manufacturing because we were lack of demand prediction model that could be applied to short product life cycle. For example, the traditional relationship between order model and Material Requirement Planning (MRP) is "planning is planning, order is order, no direct relationship between", that is, there exists some problems in the stock management of Re-Order Point (ROP) (Kumar and Meade, 2002).

Naturally, it is difficult to guarantee the accuracy of the policy-decision on material supply on such basis. Besides, when we use traditional MRP to work out a Master Production Schedule (MPS), what we think will be how much is the production of a product in a certain period not total production of a certain group of products. There is big difference between the production and actual demands of individual product. On the contrary, the difference between predicted total production and actual production of a group of products will be certainly much smaller. That is, traditional MRP could only plan for the requirement of material of individual finished products and lack of capability of material demand planning for a group of products under duplicated production. In the deployment process of Bill Of Material (BOM), although MRP combines common raw materials in calculation that is only for the consideration of batch purchase, the actual purchase strategy is still based on the production demand of MPS that often neglects the purchase benefit brought by the combination of common raw materials (Lee, 1992).

In practice, based on the uncertainty of production conditions, it is difficult to consider only the production quantity without considering the reproduction point at the same time. The (s, Q) system has been widely used in practice to deal with the inventory replenishment problem. Based on the (s, Q) system, the replenishment of product is determined by the reorder point $s$ and the optimal quantity $\mathrm{Q}$ is ordered in each replenishment period. That is, when the inventory level is lower than the reorder point $\mathrm{s}$, a reorder action with the optimal replenishment quantity $\mathrm{Q}$ is triggered. But, the (s, Q) system is seldom used in the production policy. In order to minimize the total production cost while considering imperfect production conditions; in this study, we apply the (s, Q) system to determine the reproduction point and the quantity of production in each production cycle.

In order to determine the optimal $(\mathrm{s}, \mathrm{Q})$, we must thoughtfully analyze the imperfect situations which may occur in the production process. The uncertainty of imperfect production may evolve from machine failure, product defects needed to be reworked, or both. Fortunately, these imperfect production situations can be classified into limited categories. Meanwhile, no matter what happened in a production cycle, in a new production cycle, all production conditions will be reset to normal. That means the manufacturing cycles are independent of each other. Each category of imperfect production situations will occur independently. That is, the conditional distribution of any future state (imperfect operation situation) $X_{n+1}$, given the past states $\mathrm{X}_{0}, \mathrm{X}_{1}, \ldots, \mathrm{X}_{\mathrm{n}-1}$ and the present state $\mathrm{X}_{\mathrm{n}}$, is independent of the past states and depends only on the present state. Therefore, the imperfect production process with finite states forms a Markov chain. Through analysis of this Markov chain generated from these imperfect production situations; we try to find out the long-run proportion of time that the Markov chain is in each state. Then, the optimal (s, Q) can be determined accordingly.

Introduction of 3C theory: Comparing to the relationship between order model and resource requirement plans of $3 \mathrm{C}$, the $3 \mathrm{C}$ model is an operation model that will integrate the relationship between order model and resource requirement plans. The biggest difference between 3C model and traditional model is " $3 \mathrm{C}$ accepts order only when it could do it whereas the 
traditional idea is that accepts order before confirming whether it has capability to carry out". This difference is the key to win in competition for an enterprise (Huang, 2004). The value of 3C theory in application is to help enterprises to solve the problem of resource management and reestablish global supply chain management system.

3C Theory is to classify and expand the prediction of demands from markets by the model of commonality, capacity and the replenishment of consumption with the changes of markets. Followings are their descriptions:

- The basic idea and value of commonality is to achieve the goal of reducing the cost of development, simplifying resource management, reducing the quantity of stock and providing customers with diversified products through extensive use of the strategy of "common material or resources". The characteristics of commonality are enhancing the commonality of materials and reducing the number of product varieties and considering the expression of product on internet at the stage of research and development

- The basic idea of capacity is to plan the allocation of resources through the application of theory of constrain (TOC) at the same time of accepting the order to enhance the client satisfaction and avoid delivery delay due to running out of stock or insufficient capacity

- The characteristics of capacity is that the demand of material and capacity have their ceiling, so when a manufacturer receives order, they have to consider whether material and capacity have capability to fulfill their promise to customers. It is an act according to their ability and a model that compares the material situation in the plan with the product varieties or materials selected by customer before answering to the customer

- The basic idea of consumption is a mechanism that combines the replenishment model of market demand through instant market information to buy materials when need. Such mechanism aims to achieve the goals including reduction of stock standard, fund reserve and loss due to discount of stock. The characteristics of consumption are that the materials are purchased with the changes of practical demands in the markets and emphasize on the simultaneity with the demands from the markets

Based on the definitions, the construction of $3 \mathrm{C}$ Theory in stock management system is conducted according to following procedures:
- Calculate maximum consumption rate of each material based on capacity limit: Estimated sales rate of a product, $\mathrm{TOP}_{\mathrm{p}}$, multiplying by the use amount of material $\mathrm{m}$ by the product $p, \mathrm{BOM}_{\mathrm{pm}}$; then, we could obtain the consumption rate of material $\mathrm{m}$ by the product. Then pick up the maximum value of consumption rates of material $\mathrm{m}$ by individual products to obtain $\mathrm{RBOM}_{\mathrm{m}}$, where $\mathrm{RBOM}_{\mathrm{m}}=\max \left\{\mathrm{TOP}_{\mathrm{p}} \times \mathrm{BOM}_{\mathrm{pm}}\right\}$. In fact, the $\mathrm{RBOM}_{\mathrm{m}}$ has considered the maximum sales rate of product $p, \mathrm{MSR}_{\mathrm{p}}$, is the output rate of the product in the supply chains $\mathrm{MSR}_{\mathrm{p}}=\min \left\{\mathrm{BOM}_{\mathrm{pf}}\right\}$, where $\mathrm{MOR}_{\mathrm{pf}}$ is the maximum output rate of Product $\mathrm{p}$ at production unit $\mathrm{f}$; consumption $\left(\mathrm{TOP}_{\mathrm{p}}\right.$ multiplies $\mathrm{BOM}_{\mathrm{pm}}$ ), commonality (maximum value of consumption of $\mathrm{m}$ by individual products). It is the core of $3 \mathrm{C}$ Theory.

- The material "commonality index" is used as the performance indicator of stock management. Commonality is not only a conception but also the concrete indicator that could be measured and called "commonality index". In the best situation, the commonality is 1 whereas at the worst situation, the commonality is 0 . At the best situation, the stock amount is the lowest, set as Inv $_{\text {best, }}$ the stock amount is highest at the worst

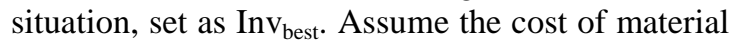
$\mathrm{m}$ is $\mathrm{Cm}$ and there are $P$ varieties of products, then:

- At the best situation, all products completely use common materials, the stock amount is:

- $\quad \operatorname{Inv}_{\text {best }}=\max _{\mathrm{p}}\left\{\mathrm{TOP}_{\mathrm{p} 1} \times \mathrm{BOM}_{\mathrm{p} 1}\right\} \times \mathrm{C}_{\mathrm{m}}$

- At the worst situation, all products completely not use common materials. So:

- $\operatorname{Inv}_{\text {worst }}=\sum_{\mathrm{p}} \sum_{\mathrm{m}} \mathrm{TOP}_{\mathrm{p}} \times \mathrm{BOM}_{\mathrm{pm}} \times \mathrm{C}_{\mathrm{m}}$ 。

- Under normal situation, the stock amount is:

- $\quad \operatorname{Inv}_{\text {pract }}=\sum_{\mathrm{m}} \mathrm{RBOM}_{\mathrm{m}} \times \mathrm{C}_{\mathrm{m}}$

- $\left.\quad \mathrm{COMI}=\left(\operatorname{Inv}_{\text {worst }}-\operatorname{Inv}_{\text {pract }}\right) /\left(\operatorname{Inv}_{\text {worst }}-\operatorname{Inv}_{\text {best }}\right)\right]$

Based on the commonality index calculated from Eq. 4, the inventory policy-decision is made by the following rules:

- While COMI is greater or equal than 0.5, an optimal $(\mathrm{R}, \mathrm{s}, \mathrm{S})$ inventory policy for material $\mathrm{m}$ is developed to maximize the total Net Present Value (NPV) for each retailer as follows. 
- $\quad \mathrm{R}$, the review period:

$\mathrm{R}=\mathrm{TBP}_{\mathrm{m}}=\mathrm{EOQ}_{\mathrm{m}} / \mathrm{RBOM}_{\mathrm{m}}$

- S, Order-Up-to-Level:

$\mathrm{S}=\mathrm{OUT}_{\mathrm{m}}=\mathrm{RBOM}_{\mathrm{m}} \times \mathrm{TBP}_{\mathrm{m}}+\mathrm{SS}_{\mathrm{m}}$

- $\quad \mathrm{s}$, reorder point

$\mathrm{s}=\mathrm{ROP}_{\mathrm{m}}=\mathrm{RBOM}_{\mathrm{m}} \times \mathrm{LT}_{\mathrm{m}}+\mathrm{SS}_{\mathrm{m}}$

where:

$\mathrm{LT}_{\mathrm{m}}=$ The lead time of purchasing material $\mathrm{m}$

$\mathrm{SS}_{\mathrm{m}}=$ The safety stock level

- While COMI is less than 0.5, an optimal (s, Q) inventory policy for material $\mathrm{m}$ is developed to maximize the total Net Present Value (NPV) for each retailer as follows:

- $\mathrm{Q}$, the economic order quantity:

$\mathrm{Q}=\mathrm{EOQ}_{\mathrm{m}}=\sqrt{\frac{2 \mathrm{RBOM}_{\mathrm{m}} \mathrm{K}}{\mathrm{H}}}$

- $\mathrm{s}$, reorder point:

$\mathrm{s}=\mathrm{ROP}_{\mathrm{m}}=\mathrm{RBOM}_{\mathrm{m}} \times$

' $\mathrm{LT}_{\mathrm{m}}+\mathrm{SS}_{\mathrm{m}}$

Categories of imperfect production and symbol explanation: Different from traditional operation, based on the $3 \mathrm{C}$ Theory, what we think will be how much is total production of a certain group of products not the production of a product in a certain period. The unreliability of machines and defects occurring in the production process are classified into eight categories by (Chang, 2002; Chen et al., 2006). When the products fall within production specifications and rework is not needed, three possible situations could be defined as follows: (ALT1) a perfect production process; (ALT2) machine breakdown happened before the production process was finished and could be repaired to finish the production process; (ALT3) machine breakdown happened before the production process was finished, but could not be repaired before the stock was sold out.

Furthermore, when defective products were found and needed to be reworked, five possible situations could be defined as follows: (ALT4) before the completion of production process and reworking process, machine did not break down; (ALT5) machine breakdown happened in the reworking process and could be repaired before the stock level was sold out; (ALT6) machine breakdown happened in the reworking process and could not be repaired before the stock level was sold out; (ALT7) machine breakdown happened before the completion of the production processing but could be repaired before the stock was sold out; (ALT8) machine breakdown happened before the completion of production processing and could not be repaired before the stock was sold out.

Without consideration of shortage incurred due to difference in external demand, the decision factors of EPQ model with the uncertainty incurred from the above mentioned eight production situations include; (1) the setup cost (S), including the setup cost of production; the additional setup cost of machine repair and the readjustment setup cost of reworking; (2) the holding cost $(\mathrm{H})$, including the holding cost of the finished goods ; the holding cost of reworking products and the additional holding cost of raw material used in the reworking process; (3) the internal failure cost incurred from the failure of reworking on defects; and (4) the shortage cost. The cost structure of EPQ can be expressed as follows:

Total Cost $=$ Setup Cost + Holding Cost + Internal Failure Cost + Shortage Cost

The cost structure in each imperfect production situation is discussed and the symbols used in this study are expressed as follows:

$\mathrm{D}_{\mathrm{r}}$ : The yearly demand of product $\mathrm{p}$

Q: Production quantity

p: Daily production rate

LT: The lead time of production setup

$\mathrm{d}_{\mathrm{m}}$ : Average daily demand of product $\mathrm{p}$

$\mathrm{P}_{\mathrm{i}}$ : Defective rate of production process, under the $i$ th imperfect production situation, where $1 \leq \mathrm{i} \leq 8$,

$\mathrm{R}_{\mathrm{i}}$ : The success ratio in reworking process, under the $i$ th imperfect production situation, where $1 \leq \mathrm{i} \leq 8$,

$\mathrm{B}_{\mathrm{i}}$ : The shortage rate in the ith imperfect production situation; when the machine breakdown happened and remained un-repaired before the stock is sold out, where $1 \leq i \leq 8$

$\mathrm{S}_{\mathrm{i}}$ : The setup cost; where $\mathrm{S}_{1}=$ the setup cost of production, $\mathrm{S}_{2}=$ the additional setup cost of machine repair and $S_{3}=$ the setup cost of the reworking process

$\mathrm{H}_{\mathrm{i}}$ : The holding cost; where $\mathrm{H}_{1}=$ the holding cost of finished goods, $\mathrm{H}_{2}=$ the holding cost of defective products and $\mathrm{H}_{3}=$ the cost of holding additional raw materials 
$\mathrm{T}_{\mathrm{i}}$ : The downtime incurred from machine repair, under the $i^{\text {th }}$ imperfect production situation, where $1 \leq \mathrm{i} \leq 8$.

$\mathrm{W}_{\mathrm{i}}$ : The proportion of holding additional raw material during the downtime in the $i$ th imperfect production situation, where $1 \leq \mathrm{i} \leq 8$.

$\mathrm{V}$ : The internal failure cost incurred from machine breakdown

B: The shortage cost incurred from machine breakdown and/or defectiveness

An Adaptive (s, Q) production system with Markov process: For a Markov chain, the conditional distribution of any future state $X_{n+1}$, given the past states $X_{0}, X_{1, \ldots,} X_{n}{ }_{1}$ and the present state $X_{n}$, is independent of the past states and depends only on the present state. If $X_{n}=i$, then the process is said to be in state $\mathrm{i}$ at time $\mathrm{n}$. We suppose that whenever the process is in state $\mathrm{i}$, there is a fixed probability $\mathrm{P}_{\mathrm{ij}}$ that it will next be in state $\mathrm{j}$. That is, we suppose that:

$$
\begin{aligned}
& P\left\{X_{n+1}=j \mid X_{n}=i, X_{n-1}=i_{n-1}\right. \\
& \left., \ldots, X_{1}=i_{1}, X_{0}=i_{0}\right\}=P_{i j}
\end{aligned}
$$

for all states $i_{0}, i_{1}, \ldots, i_{n-1}, i, j$ and all $n \geq 0$. The value $P_{i j}$ represents the probability that the process will, when in state $\mathrm{i}$, next make a transition into state $\mathrm{j}$. Since the probabilities are nonnegative and since the process must make a transition into some state, we can define the matrix of one-step transition probabilities $\mathrm{P}_{\mathrm{ij}}$ as:

$$
\mathrm{P}=\left\|\begin{array}{cccc}
\mathrm{P}_{00} & \mathrm{P}_{01} & \mathrm{P}_{02} & \ldots \\
\mathrm{P}_{10} & \mathrm{P}_{11} & \mathrm{P}_{12} & \ldots \\
: & : & : & \\
\mathrm{P}_{\mathrm{i} 0} & \mathrm{P}_{\mathrm{i} 1} & \mathrm{P}_{\mathrm{i} 2} & \ldots \\
: & : & : &
\end{array}\right\|
$$

Where:

$$
P_{i j} \geq 0, i, j \geq 0 ; \sum_{j=0}^{\infty} P_{i j}=1, i=0,1,2, \ldots
$$

Then, the n-step transition probabilities $P_{i j}^{n}$ can be defined as the probability that a process in state $i$ will be in state $\mathrm{j}$ after $\mathrm{n}$ additional transitions.

That is:

$$
P_{i j}^{n}=P\left\{X_{n+k}=j \mid X_{k}=i\right\}, n \geq 0, i, j \geq 0 \text {, and } P_{i j}^{1}=P_{i j}
$$

The Chapman-Kolmogorov equation provides a method for computing these n-step transition probabilities as:

$$
\mathrm{P}_{\mathrm{ij}}^{\mathrm{n}+\mathrm{m}}=\sum_{\mathrm{k}=0}^{\infty} \mathrm{P}_{\mathrm{ik}}^{\mathrm{n}} \mathrm{P}_{\mathrm{kj}}^{\mathrm{m}} \text { for all } \mathrm{n}, \mathrm{m} \geq 0, \forall \mathrm{i}, \mathrm{j}
$$

By Scheffe (1947) Theorem, which states that if $\mathrm{g}_{\mathrm{n}}$ is a sequence of densities converging at almost all $\mathrm{x}$ to $f$, then $\int\left|g_{n}-f\right| \rightarrow 0$ as $n \rightarrow \infty$. Then, through the limit probability (Meyer et al., 1979), an irreducible positive recurrent Markov chain $\lim _{n \rightarrow \infty} P_{i j}^{n}$ exists and is independent of i. Furthermore, letting $\pi_{j}=\lim _{n \rightarrow \infty} P_{i j}^{n}, j \geq 0$ then $\pi_{j}$ is the unique solution of:

$\left\{\begin{array}{c}\pi_{j}=\sum_{i=0}^{\infty} \pi_{i} P_{i j}, \quad j \geq 0 \\ \sum_{j=0}^{\infty} \pi_{j}=1\end{array}\right.$

Since production processes with imperfect production conditions can be classified into one of eight imperfect categories which are independent of each other, the imperfect production process forms a Markov chain. Then, the transition probability $\mathrm{P}_{\mathrm{ij}}$ can be redefined as the probability of the production process, when in situation i (ALT i), will next make a transition into situation $\mathrm{j}$ (ALT $\mathrm{j}$ ). Therefore, based on these limiting probabilities in each state (imperfect situation) of Markov chain, the optimal production quantity (Q) can also be formulated as:

The Optimal Production Quantity (Q)

$=$ the expected production quantity of the EPQ in each state of Markov chain multiplies the limiting probability in each related state $=\sum_{\mathrm{j}=1}^{8} \pi_{\mathrm{j}} \times \mathrm{EPQ}_{\mathrm{j}}$

The Reproduction Point (s) under the customer service level 1- $\alpha$ with normal distribution approach:

$==\mathrm{d}_{\mathrm{m}} \times \mathrm{LT}+\mathrm{z}_{\alpha / 2} \times \sqrt{\mathrm{LT}} \times \sqrt{\sum_{\mathrm{j}=1}^{8} \pi_{\mathrm{j}}\left(\mathrm{EPQ}_{\mathrm{j}}-\mathrm{Q}\right)^{2}}$

Determination of the economic production quantity in each imperfect situation: The EPQ in each production category based on its probability for producing product $\mathrm{p}$ can be calculated as follows. 
Products produced from production processed by the machine, which are all within the specifications, thus with no defects and unnecessary reworking and zero storage cost for remaking, the production relevant cost is:

$$
\begin{aligned}
& \mathrm{TC}_{\mathrm{ALT1}}(\mathrm{Q})=\mathrm{S}_{1} \times \mathrm{D}_{\mathrm{p}} / \mathrm{Q}+\mathrm{H}_{1} \times \mathrm{Q} / 2 \times\left(\mathrm{p}-\mathrm{d}_{\mathrm{p}}\right) / \mathrm{p} \\
& \mathrm{EPQ}_{1}=\sqrt{\frac{2 \mathrm{~S}_{1} \mathrm{D}_{\mathrm{p}}}{\mathrm{H}_{1}} \times \frac{\mathrm{p}}{\mathrm{p}-\mathrm{d}_{\mathrm{p}}}}
\end{aligned}
$$

ALT2: Machine breakdown happened before the production process was finished and could be repaired to finish the production process.

Considering this condition in which machine breakdown happened before the completion of the raw materials, it generates additional costs of machine repair, machine preparation and the holding cost of raw materials during the downtime; meanwhile it reduces the holding cost of finished goods during the downtime. Its production relevant cost is:

$$
\begin{aligned}
& \mathrm{TC}_{\mathrm{ALT2}}(\mathrm{Q})=\left(\mathrm{S}_{1}+\mathrm{S}_{2}\right) \times \mathrm{D}_{\mathrm{p}} / \mathrm{Q}+\mathrm{H}_{1} \times \mathrm{Q} / 2 \times \\
& \left(\mathrm{p}-\mathrm{d}_{\mathrm{p}}\right) / \mathrm{p}+\left(\mathrm{H}_{3}-\mathrm{H}_{1}\right) \mathrm{W}_{2} \mathrm{~T}_{2} \mathrm{Q} \\
& \mathrm{EPQ}_{2}=\left(\frac{2\left(\mathrm{~S}_{1}+\mathrm{S}_{2}\right) \mathrm{D}_{\mathrm{p}}}{\mathrm{H}_{1} \times\left(\mathrm{p}-\mathrm{d}_{\mathrm{p}}\right) / \mathrm{p}+2\left(\mathrm{H}_{3}-\mathrm{H}_{1}\right) \mathrm{W}_{2} \mathrm{~T}_{2}}\right)^{1 / 2}
\end{aligned}
$$

ALT3: Machine breakdown happened before the production process was finished, but could not be repaired before the stock was sold out.

Incomplete production procedure can be caused by the condition in which machine breakdown has occurred but, at the time, cannot be repaired before the stock is sold out. Therefore, it will generate additional preparation cost, additional raw material storage cost, reduction in holding cost of finished goods and delay in batch production time frame. In addition, because the machine is broken down but, at the time, cannot be repaired before stock is sold out, it will increase the shortage cost of stock. Its relevant production cost is:

$$
\begin{aligned}
& \mathrm{TC}_{\mathrm{ALT3}}=\left(\mathrm{S}_{1}+\mathrm{S}_{2}\right) \times \mathrm{D}_{\mathrm{p}} / \mathrm{Q}+\mathrm{H}_{1}\left(1-\mathrm{B}_{3}\right) \\
& \times \mathrm{Q} / 2 \times\left(\mathrm{p}-\mathrm{d}_{\mathrm{p}}\right) / \mathrm{p}+ \\
& {\left[\left(\mathrm{H}_{3}-\mathrm{H}_{1}\right) \mathrm{W}_{3} \mathrm{~T}_{3}+(\mathrm{B}+\mathrm{V}) \mathrm{B}_{3}\right] \times \mathrm{Q}} \\
& \mathrm{EPQ}_{3}=\left(\begin{array}{c}
\frac{2\left(\mathrm{~S}_{1}+\mathrm{S}_{2}\right) \mathrm{D}_{\mathrm{p}}}{\mathrm{H}_{1}\left(1-\mathrm{B}_{3}\right) \times\left(\mathrm{p}-\mathrm{d}_{\mathrm{p}}\right) / \mathrm{p}+2} \\
{\left[\left(\mathrm{H}_{3}-\mathrm{H}_{1}\right) \mathrm{W}_{3} \mathrm{~T}_{3}+(\mathrm{B}+\mathrm{V}) \mathrm{B}_{3}\right]}
\end{array}\right)^{1 / 2}
\end{aligned}
$$

ALT4: Before the completion of production process and reworking process, machine did not break down.

Under this condition, because there existed the possibility of reworking, it will generate additional cost of reproduction setup cost and the holding cost of defects. Because of the existence of defective machine, the holding cost of the finished goods will be reduced, but on the contrary, there is the possibility of additional internal failure and shortage cost and the holding cost of additional raw materials will increase during the reworking process. Its relevant production cost is:

$$
\begin{aligned}
& \mathrm{TC}_{\mathrm{ALT} 4}(\mathrm{Q})=\left(\mathrm{S}_{1}+\mathrm{S}_{3}\right) \times \mathrm{D}_{\mathrm{p}} / \mathrm{Q}+(\mathrm{B}+\mathrm{V}) \mathrm{P}_{4}\left(1-\mathrm{R}_{4}\right) \times \mathrm{Q}+ \\
& \left\{\mathrm{H}_{1} \times\left[\left(1-\mathrm{P}_{4}\right)+\mathrm{P}_{4} \mathrm{R}_{4}\right]+\left(\mathrm{H}_{2}+\mathrm{H}_{3}\right)\right. \\
& \left.\mathrm{P}_{4}\left(1-\mathrm{R}_{4}\right)\right\} \times \mathrm{Q} / 2 \times\left(\mathrm{p}-\mathrm{d}_{\mathrm{p}}\right) / \mathrm{p} \\
& \mathrm{EPQ}_{4}=\left(\frac{2\left(\mathrm{~S}_{1}+\mathrm{S}_{3}\right) \mathrm{D}_{\mathrm{p}}}{\mathrm{K}}\right)^{1 / 2}
\end{aligned}
$$

Where:

$$
\begin{aligned}
& \mathrm{K}=\left\{\mathrm{H}_{1}\left[\left(1-\mathrm{P}_{4}\right)+\mathrm{P}_{4} \mathrm{R}_{4}\right]+\left(\mathrm{H}_{2}+\mathrm{H}_{3}\right) \mathrm{P}_{4}\left(1-\mathrm{R}_{4}\right)\right\} \times \\
& \left(\mathrm{p}-\mathrm{d}_{\mathrm{p}}\right) / \mathrm{p}+2(\mathrm{~B}+\mathrm{V}) \mathrm{P}_{4}\left(1-\mathrm{R}_{4}\right)
\end{aligned}
$$

LT5: Machine breakdown happened in the reworking process and could be repaired before the stock level was sold out.

Because under this condition, where machine breakdown happened during the reworking process, it will generate additional reproduction preparation cost, machine preparation cost, the holding cost of defects and additional raw materials, a reduction in the holding cost of finished goods and additional internal failure cost and shortage cost during reworking process. Its relevant production cost is:

$$
\begin{aligned}
& \mathrm{TC}_{\mathrm{ALT5}}(\mathrm{Q})=\left(\mathrm{S}_{1}+\mathrm{S}_{2}+\mathrm{S}_{3}\right) \times \mathrm{D}_{\mathrm{p}} / \\
& \mathrm{Q}+\left(\mathrm{H}_{3}-\mathrm{H}_{1}\right) \mathrm{W}_{5} \mathrm{~T}_{5} \mathrm{Q}+ \\
& \left\{\mathrm{H}_{1} \times\left[\left(1-\mathrm{P}_{5}\right)+\mathrm{P}_{5} \mathrm{R}_{5}\right]+\mathrm{H}_{2} \mathrm{P}_{5}\left(1-\mathrm{R}_{5}\right)\right\} \\
& \times \mathrm{Q} / 2 \times\left(\mathrm{p}-\mathrm{d}_{\mathrm{p}}\right) / \mathrm{p} \\
& \mathrm{EPQ}_{5}=\left(\frac{2\left(\mathrm{~S}_{1}+\mathrm{S}_{2}+\mathrm{S}_{3}\right) \mathrm{D}_{\mathrm{p}}}{\mathrm{K}}\right)^{1 / 2}
\end{aligned}
$$

Where:

$$
\begin{aligned}
& \mathrm{K}=\left\{\mathrm{H}_{1} \times\left[\left(1-\mathrm{P}_{5}\right)+\mathrm{P}_{5} \mathrm{R}_{5}\right]+\mathrm{H}_{2} \mathrm{P}_{5}\left(1-\mathrm{R}_{5}\right)\right\} \times\left(\mathrm{p}-\mathrm{d}_{\mathrm{p}}\right) \\
& / \mathrm{p}+2\left(\mathrm{H}_{3}-\mathrm{H}_{1}\right) \mathrm{W}_{5} \mathrm{~T}_{5}
\end{aligned}
$$


ALT 6: Machine breakdown happened in the reworking process and could not be repaired before the stock level was sold out.

Under this condition, the breakdown machine will cause incomplete reworking process. Therefore, it will generate additional reproduction preparation cost, machine preparation cost, the holding cost of defects and additional raw materials, the internal failure cost, a reduction in the holding cost for finished goods and shortage cost. Its relevant production cost is:

$$
\begin{aligned}
& \mathrm{TC}_{\mathrm{ALT} 6}(\mathrm{Q})=\left(\mathrm{S}_{1}+\mathrm{S}_{2}+\mathrm{S}_{3}\right) \times \mathrm{D}_{\mathrm{p}} / \mathrm{Q}+ \\
& {\left[\left(\mathrm{H}_{3}-\mathrm{H}_{1}\right) \mathrm{W}_{6} \mathrm{~T}_{6}+(\mathrm{B}+\mathrm{V}) \mathrm{P}_{6}\left(1-\mathrm{R}_{6}\right)\right] \times \mathrm{Q}} \\
& \left\{\mathrm{H}_{1} \times\left[\left(1-\mathrm{P}_{6}\right)\left(1-\mathrm{B}_{6}\right)+\mathrm{P}_{6} \mathrm{R}_{6}\right]+\mathrm{H}_{2} \mathrm{P}_{6}\right. \\
& \left.\left(1-\mathrm{R}_{6}\right)\left(1-\mathrm{B}_{6}\right)\right\} \times \mathrm{Q} / 2 \times\left(\mathrm{p}-\mathrm{d}_{\mathrm{p}}\right) / \mathrm{p} \\
& \left\{\mathrm{H}_{1} \times\left[\left(1-\mathrm{P}_{6}\right)\left(1-\mathrm{B}_{6}\right)+\mathrm{P}_{6} \mathrm{R}_{6}\right]+\mathrm{H}_{2} \mathrm{P}_{6}\left(1-\mathrm{R}_{6}\right)\right. \\
& \left.\left(1-\mathrm{B}_{6}\right)\right\} \times \mathrm{Q} / 2 \times\left(\mathrm{p}-\mathrm{d}_{\mathrm{p}}\right) / \mathrm{p} \\
& \mathrm{EPQ}_{6}=\left(\frac{2\left(\mathrm{~S}_{1}+\mathrm{S}_{2}+\mathrm{S}_{3}\right) \mathrm{D}_{\mathrm{p}}}{\mathrm{K}}\right)^{1 / 2}
\end{aligned}
$$

Where:

$$
\begin{aligned}
& \mathrm{K}=\left\{\mathrm{H}_{1} \times\left[\left(1-\mathrm{P}_{6}\right)\left(1-\mathrm{B}_{6}\right)+\mathrm{P}_{6} \mathrm{R}_{6}\right]+\mathrm{H}_{2} \mathrm{P}_{6}\right. \\
& \left.\left(1-\mathrm{R}_{6}\right)\left(1-\mathrm{B}_{6}\right)\right\} \times\left(\mathrm{p}-\mathrm{d}_{\mathrm{p}}\right) / \mathrm{p}+ \\
& 2\left[\left(\mathrm{H}_{3}-\mathrm{H}_{1}\right) \mathrm{W}_{6} \mathrm{~T}_{6}+(\mathrm{V}+\mathrm{B}) \mathrm{P}_{6}\left(1-\mathrm{R}_{6}\right)\right]
\end{aligned}
$$

ALT 7: Machine breakdown happened before the completion of production processing but could be repaired before the stock was sold out.

Under this condition, the machine breakdown happened before the batch production of the raw material is finished, during the waiting period for repairs, it will increase the extra holding cost of raw material and reduce the holding cost of finished goods, at the same time, it will generate additional machine setup cost, reproduction setup cost, repetitive storage cost and the internal failure cost and shortage cost incurred from reworking process. The production cost is:

$$
\begin{aligned}
& \mathrm{TC}_{\mathrm{ALT} 7}(\mathrm{Q})=\left(\mathrm{S}_{1}+\mathrm{S}_{2}+\mathrm{S}_{3}\right) \times \mathrm{D}_{\mathrm{p}} / \mathrm{Q}+ \\
& \left(\mathrm{H}_{3}-\mathrm{H}_{1}\right) \mathrm{W}_{7} \mathrm{~T}_{7} \mathrm{Q}+ \\
& \left\{\left[\mathrm{H}_{1}\left[\left(1-\mathrm{P}_{7}\right)+\mathrm{P}_{7} \mathrm{R}_{7}\right]+\mathrm{H}_{2} \mathrm{P}_{7}\left(1-\mathrm{R}_{7}\right)\right\}\right. \\
& \times \mathrm{Q} / 2 \times\left(\mathrm{p}-\mathrm{d}_{\mathrm{p}}\right) / \mathrm{p} \\
& \mathrm{EPQ}_{7}=\left(\frac{2\left(\mathrm{~S}_{1}+\mathrm{S}_{2}+\mathrm{S}_{3}\right) \mathrm{D}_{\mathrm{p}}}{\mathrm{K}}\right)^{1 / 2}
\end{aligned}
$$

Where:

$$
\begin{aligned}
& \mathrm{K}=\left\{\mathrm{H}_{1} \times\left[\left(1-\mathrm{P}_{7}\right)+\mathrm{P}_{7} \mathrm{R}_{7}\right]+\mathrm{H}_{2} \mathrm{P}_{7}\left(1-\mathrm{R}_{7}\right)\right\} \times \\
& \left(\mathrm{p}-\mathrm{d}_{\mathrm{p}}\right) / \mathrm{p}+2\left(\mathrm{H}_{3}-\mathrm{H}_{1}\right) \mathrm{W}_{7} \mathrm{~T}_{7}
\end{aligned}
$$

ALT 8: Machine breakdown happened before the completion of production processing and could not be repaired before the stock was sold out.

Under this condition, the machine breakdown happened before the completion of production process, but was unable to be repaired before the stock is sold out. This will cause production severance and incomplete production; therefore, it will generate additional machine repair setup cost, the holding cost of defects, a reduction in the holding cost of finished goods, additional raw material holding cost and shortage cost during the machine downtime. Its production cost is:

$$
\begin{aligned}
& \mathrm{TC}_{\text {ALT8 }}(\mathrm{Q})=\left(\mathrm{S}_{1}+\mathrm{S}_{2}\right) \times \mathrm{D}_{\mathrm{p}} / \mathrm{Q}+ \\
& {\left[\left(\mathrm{H}_{3}-\mathrm{H}_{1}\right) \mathrm{W}_{8} \mathrm{~T}_{8}+(\mathrm{B}+\mathrm{V}) \mathrm{B}_{8}\right] \times \mathrm{Q}} \\
& {\left[\mathrm{H}_{1}\left(1-\mathrm{P}_{8}\right)\left(1-\mathrm{B}_{8}\right)+\mathrm{H}_{2} \mathrm{P}_{8}\left(1-\mathrm{B}_{8}\right)\right] \times \mathrm{Q} / 2 \times\left(\mathrm{p}-\mathrm{d}_{\mathrm{p}}\right) / \mathrm{p}} \\
& \mathrm{EPQ}_{8}=\left(\frac{2\left(\mathrm{~S}_{1}+\mathrm{S}_{2}\right) \mathrm{D}_{\mathrm{p}}}{\mathrm{K}}\right)^{1 / 2}
\end{aligned}
$$

Where:

$$
\begin{aligned}
& \mathrm{K}=\left\{\mathrm{H}_{1}\left(1-\mathrm{P}_{8}\right)\left(1-\mathrm{R}_{8}\right)+\mathrm{H}_{2} \mathrm{P}_{8}\left(1-\mathrm{R}_{8}\right)\right\} \times\left(\mathrm{p}-\mathrm{d}_{\mathrm{p}}\right) / \mathrm{p} \\
& +2\left[\left(\mathrm{H}_{3}-\mathrm{H}_{1}\right) \mathrm{W}_{8} \mathrm{~T}_{8}+(\mathrm{B}+\mathrm{V}) \mathrm{B}_{8}\right]
\end{aligned}
$$

Case simulation and result analysis: Being a supplier in the do-it-yourself furnishings supply chain, company $\mathrm{A}$ is an office furnishings manufacturer. They provide different styles of wood-made office furnishings for customers to do it for themselves. The operations in production line include: steeling, shaving, drilling and lacquering. Basically, company uses the traditional EPQ model to determine the optimal production quantity in each production cycle. But, with semi-automatic production, the management has been beset by disruptions, which incurred a lot of customer complain, from production resulting in machine brake down and rework on defective products. The machine downtime might last from a few hours to several days. Except that machine brake down might happen in production period, the defective products also incurred from production processes. As a result, these supply disruptions highly increase the supply uncertainty in supply chain management. So, how to effectively control the imperfect production condition in production processes 
will be the most important issue for company A to cope with. In this situation, we propose an adaptive (s, Q) production system with Markov process and $(\mathrm{R}, \mathrm{s}, \mathrm{S})$ procurement system with 3C Theory to solve company A's disruption problem in order to smooth the supply disruptions in whole supply chain.

Determination of $(\mathbf{s}, \mathbf{Q})$ production system: Take the most popular product category as an example, this category includes 3 types of desks, named desk1, desk 2 and desk3. Take the desk1 as an example, the production manager of company $\mathrm{A}$, according to the past desk production experience and historical data, as also the past production process problems encountered from machine unreliability and defects, induces the main decision-making cost factor of influencing desk production work, which contains; the production setup $\operatorname{cost}\left(\mathrm{S}_{1}\right)$, the machine maintain setup $\cos t\left(\mathrm{~S}_{2}\right)$, the reproduction setup $\cos t\left(\mathrm{~S}_{3}\right)$, the finished product holding $\operatorname{cost}\left(\mathrm{H}_{1}\right)$; the repetition holding $\operatorname{cost}\left(\mathrm{H}_{2}\right)$; the additional raw material holding $\operatorname{cost}\left(\mathrm{H}_{3}\right)$, the internal failure $\operatorname{cost}(\mathrm{V})$ and the shortage $\operatorname{cost}(\mathrm{B})$. Data provided by company A, are expressed as follows:

- The normal workday of this company in a year is 250 days; the daily demand quantity is 120 desks in its series of products, the production rate is 150 desks per day and the lead time for production is one day.

- $\left(\mathrm{S}_{1}, \mathrm{~S}_{2}, \mathrm{~S}_{3}, \mathrm{H}_{1}, \mathrm{H}_{2}, \mathrm{H}_{3}, \mathrm{~V}, \mathrm{~B}\right)=(200,300,250,20$, $18,15,10,100)$

- The probabilities of defects incurred from production $\left(\mathrm{P}_{\mathrm{i}}\right)$ are

- $\quad\left(\mathrm{P}_{1}, \mathrm{P}_{2}, \mathrm{P}_{3}, \mathrm{P}_{4}, \mathrm{P}_{5}, \mathrm{P}_{6}, \mathrm{P}_{7}, \mathrm{P}_{8}\right)=(0,0,0,0.04,0.03$, $0.08,0.10,0.08$ )

- The success rates of reworking on defects $\left(\mathrm{R}_{\mathrm{i}}\right)$ are

- $\left(\mathrm{R}_{1}, \mathrm{R}_{2}, \mathrm{R}_{3}, \mathrm{R}_{4}, \mathrm{R}_{5}, \mathrm{R}_{6}, \mathrm{R}_{7}, \mathrm{R}_{8}\right)=(1,1,1,0.9,0.8$, $0.8,0.7,0.7)$.

- The shortage rates $\left(\mathrm{B}_{\mathrm{i}}\right)$ incurred from machine breakdown and unable to repair it before the stock is sold out are

- $\left(\mathrm{B}_{1}, \mathrm{~B}_{2}, \mathrm{~B}_{3}, \mathrm{~B}_{4}, \mathrm{~B}_{5}, \mathrm{~B}_{6}, \mathrm{~B}_{7}, \mathrm{~B}_{8}\right)=(0,0,0.3,0,0$, $0.03,0,0.3)$.

- The maintenance time (in days) consumed by the machine, respectively, are

- $\quad\left(\mathrm{T}_{1}, \mathrm{~T}_{2}, \mathrm{~T}_{3}, \mathrm{~T}_{4}, \mathrm{~T}_{5}, \mathrm{~T}_{6}, \mathrm{~T}_{7}, \mathrm{~T}_{8}\right)=(0,1,2,0,1,1,1,3)$

- The average proportion of holding additional raw material in each production category, respectively, are

- $\left(\mathrm{W}_{1}, \mathrm{~W}_{2}, \mathrm{~W}_{3}, \mathrm{~W}_{4}, \mathrm{~W}_{5}, \mathrm{~W}_{6}, \mathrm{~W}_{7}, \mathrm{~W}_{8}\right)=(0,0.15,0.2$, $0,0.2,0.3,0.25,0.3)$.

- The transition probabilities matrix of production process is:

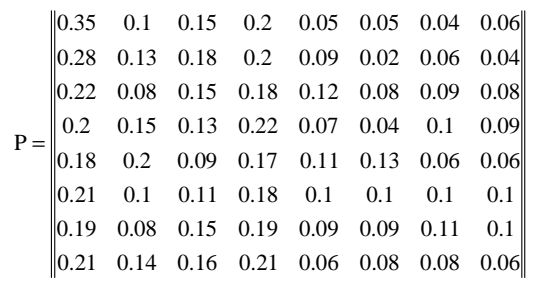

From Eq. 12, the limiting probabilities of imperfect production situations is:

$\left(\pi_{1}, \pi_{2}, \pi_{3}, \pi_{4}, \pi_{5}, \pi_{6}, \pi_{7}, \pi_{8}\right)=(0.2488,0.1200,0.1430$, $0.1974,0.0805,0.0635,0.0749,0.0719)$

From Eq. 17a-24a, the EPQ of each imperfect production situation is:

$\left(\mathrm{EPQ}_{1}, \mathrm{EPQ}_{2}, \mathrm{EPQ}_{3}, \mathrm{EPQ}_{4}, \mathrm{EPQ}_{5}, \mathrm{EPQ}_{6}, \mathrm{EPQ}_{7}, \mathrm{EPQ}_{8}\right)=$ $(1732,3464,680,2350,3875,3198,5500,718)$

Then, the (s, Q) production system under the customer service level $1-\alpha=0.90$ can be calculated as follows:

$$
\begin{aligned}
& \mathrm{Q}=\text { The targeted production level }= \\
& \sum_{\mathrm{i}=1}^{8} \pi_{\mathrm{i}} \times \mathrm{EPQ}_{\mathrm{i}}=2386 \\
& \sigma=\text { The } \quad \text { standard } \\
& \sqrt{\sum_{\mathrm{i}=1}^{8} \pi_{\mathrm{i}}\left(\mathrm{EPQ}_{\mathrm{i}}-\mathrm{Q}\right)^{2}}=1345 \\
& \mathrm{~S}= \\
& \mathrm{The} \quad \text { reproduction } \\
& \mathrm{d} \times \mathrm{LT}+\mathrm{z}_{0.05} \times \sigma \times \sqrt{\mathrm{LT}}=2219
\end{aligned}
$$

From the above calculation, the optimal (s, Q) production policy is $(2219,2386)$. That is, the company should produce an optimal quantity of 2,386 desks in each production cycle; meanwhile, a production process is set up when the inventory level is below 2,219 desks.

If this company uses the traditional EPQ model, i.e., it does not consider the defect occurrence and the machine unreliability, as it is similar to the first categorized situation, its Economical Production Quantity is EPQ $=1,732$. Evidently, under the condition when defect occurrence and the machine unreliability are considered, the Targeted Economical Production Quantity is greater than the traditional Economical Production Quantity; this is to avoid the mechanical breakdown in the production process or the possible occurrence of the reproduction failure in the reworking process, which leads to the increase in the production quantity in the shortage situation. 
J. Math. \& Stat., 7 (3): 187-197, 2011

Table 1: The Table of Pull (TOP) and Bill of Material (BOM) of Products

\begin{tabular}{|c|c|c|c|c|c|c|}
\hline \multirow[b]{2}{*}{ Product } & \multirow[b]{2}{*}{$\mathrm{TOP}_{\mathrm{p}}$} & \multicolumn{5}{|l|}{$\mathrm{BOM}_{\mathrm{pm}}$} \\
\hline & & Wood_1 & Wood_2 & Wood_3 & Comp_1 & Comp_2 \\
\hline$\overline{\text { Desk1 }}$ & 30,000 & 0 & 1 & 0 & 3 & 1 \\
\hline Desk2 & 30,000 & 1 & 1 & 0 & 1 & 3 \\
\hline Desk3 & 20,000 & 1 & 0 & 1 & 2 & 2 \\
\hline $\mathrm{C}_{\mathrm{m}}$ & & 200 & 210 & 220 & 100 & 80 \\
\hline
\end{tabular}

Table 2: The Computing Result of Each Material Applied in 3C Theory

\begin{tabular}{lllllll} 
Material & Wood_1 & Wood_2 & Wood_3 & Comp_1 & Comp_2 & Total \\
\hline MRP $_{\mathrm{m}}$ & 50,000 & 60,000 & 20,000 & 160,000 & 160,000 & \\
RBOM $_{\mathrm{m}}$ & 30,000 & 30,000 & 20,000 & 90,000 & 90,000 & \\
Lnv $_{\text {worst }}$ & $10.000,000$ & $12,600,000$ & $4,400,000$ & $16,000,000$ & $12,800,000$ & $55,800,000$ \\
Lnvpract & $6,000,000$ & $6,300,000$ & $4,400,000$ & $9,000,000$ & $7,200,000$ & $32,900,000$ \\
COMI & & & & & & 0.6156 \\
\hline
\end{tabular}

Table 3: Order Policy Analysis

\begin{tabular}{|c|c|c|c|c|c|}
\hline \multicolumn{3}{|l|}{$\begin{array}{l}\text { Hold cost } \\
\text { Order Cost }\end{array}$} & \multicolumn{3}{|l|}{$\begin{array}{l}\mathrm{C}_{\mathrm{m}} \times 10 \% \\
100\end{array}$} \\
\hline Material m & Wood_1 & Wood_2 & Wood_3 & Comp_1 & Comp_2 \\
\hline$\overline{L T}_{\mathrm{m}}$ (Year) & $2 / 300$ & $3 / 300$ & $2 / 300$ & $4 / 300$ & $4 / 300$ \\
\hline $\mathrm{TBP}_{\mathrm{m}}$ & 0.02357 & 0.02520 & 0.01421 & 0.05963 & 0.06667 \\
\hline $\mathrm{EOQ}_{\mathrm{m}}$ & 708 & 756 & 427 & 1,789 & 2,000 \\
\hline $\mathrm{OUT}_{\mathrm{m}}$ & 1,008 & 1,056 & 627 & 2,689 & 2,900 \\
\hline $\mathrm{ROP}_{\mathrm{m}}$ & 500 & 900 & 334 & 2,100 & 2,100 \\
\hline $\mathrm{SS}_{\mathrm{m}}$ & 300 & 300 & 200 & 900 & 900 \\
\hline
\end{tabular}

Determination of ( $R, S, S)$ procurement system: There are three wood modules and two component modules and both are independent materials that could be used to assembly three varieties of desks. The data which is obtained from the analysis according to $3 \mathrm{C}$ Theory introduced by the research is as follows.

First, according the given data on Table $1, \mathrm{MRP}_{\mathrm{m}}$ and $\mathrm{RBOM}_{\mathrm{m}}$ are defined as $\mathrm{MRP}_{\mathrm{m}}=\sum_{\mathrm{p}} \mathrm{TOP}_{\mathrm{p}} \times \mathrm{BOM}_{\mathrm{m}}$ and $\mathrm{RBOM}_{\mathrm{m}}=\max \left\{\mathrm{TOP}_{\mathrm{p}} \times \mathrm{BOM}_{\mathrm{pm}}\right\}$. Then, take Wood_1 as an example, the requirement for Wood_1 based on $\mathrm{MRP}_{\mathrm{m}}$ and $\mathrm{RBOM}_{\mathrm{m}}$ can be calculated as $\mathrm{MRP}_{\mathrm{m}}$ $=30,000 * 0+30,000 * 1+20,000 * 1=50,000$ and $\mathrm{RBOM}_{\mathrm{m}}=$ $\max \{30,000 * 0,30,000 * 1,20,000 * 1\}=30,000$. As a result, the requirement for each material can be calculated accordingly and resulted on Table 2 .

Second, according to the material "commonality index", the $\operatorname{Inv}_{\text {best }}=\sum_{\mathrm{m}} \mathrm{TOP}_{1 \mathrm{~m}} \times \mathrm{BOM}_{1 \mathrm{~m}} \times \mathrm{C}_{\mathrm{m}}$, $\operatorname{Inv}_{\text {worst }}=\mathrm{P} \times \operatorname{Inv}_{\text {best }}$ and $\operatorname{Inv}_{\text {pract }}=\sum_{\mathrm{m}} \operatorname{RBOM}_{\mathrm{m}} \times \mathrm{C}_{\mathrm{m}}$, then, $\operatorname{lnv}_{\text {worst }}=(50,000 * 200+60,000 * 210+20,000 * 220+$ $160,000 * 100+160,000 * 80)=55,800,000$ and $\operatorname{lnv}_{\mathrm{worst}}=$ $(30,000 * 200+30,000 * 210+20,000 * 220+$ $90,000 * 100+90,000 * 80)=32,900,000$. After accumulating all materials, the $\operatorname{lnv}_{\text {wors }}$ and lnvpract are resulted in Table 2 and the commonality index (COMI) can be calculated as:
COMI $=\left(\operatorname{Inv}_{\text {worst }}-\operatorname{Inv}_{\text {pract }}\right) /\left(\operatorname{Inv}_{\text {worst }}-\operatorname{Inv}_{\text {best }}\right)=(3 / 2) *(1-$
$=[\mathrm{p} /(\mathrm{p}-1)]\left[1-\operatorname{Inv}_{\text {pract }} / \operatorname{Inv}_{\text {worst }}\right]$ $329 / 558)=0.6156$.

Third, according the COMI obtained from Table 2, the order policy of each material can be generated and resulted in Table 3. For example, for Wood_1 calculated with Eq. 5-7, $\mathrm{EOQ}_{\mathrm{m}}=\sqrt{2 * 100 * 50,000 / 200 * 0.1}=708$, $\mathrm{TBP}_{\mathrm{m}}=708 / 30,000=0.02357, \mathrm{SS}_{\mathrm{m}}=\mathrm{RBOM}_{\mathrm{m}} \times 1 \%=$ $30,000 * 0.01=300, \mathrm{OUT}_{\mathrm{m}}=30,000 * 0.02357+300=$ 1,008 and $\mathrm{ROP}_{\mathrm{m}}=30,000 *(2 / 300)+300=500$ :

Then, based on the calculation mentioned above, an adaptive ( $\mathrm{R}, \mathrm{s}, \mathrm{S})$ procurement system can be generated. Take Wood_1 as an example, its optimal procurement system will be $(\mathrm{R}, \mathrm{s}, \mathrm{S})=(0.02357,500$, 1,008); that is, the optimal purchasing quantity for Wood_1 is 1,008 unit per time and procurement cycle is 0.02357 year. The optimal safety stock setting will be 300 units and the reorder point is 500 units.

\section{CONCLUSION}

In this study, we have developed a practical methodology for establishing an adaptive productionprocurement system in the supply chain problems under supply disruptions. This method use the Limiting 
Probability of Markov Chain as the decision-making pattern to provide an adaptive (s, Q) production system, on application of the EPQ pattern with thoughtful consideration of the possibility of machine unreliability and defect occurrence, for an enterprise to execute the production processes efficiently and to smooth disruptions incurred from production processes effectively. Meanwhile, based on 3C Theory, an adaptive (R, s, S) procurement system based on the production process also can be determined to meet the production requirements. We have provided empirical results for furnishings supply chain. Our results reveal the computational efficacy of the proposed method. Furthermore, we have demonstrated that the candidate solutions identified by the proposed method are not only superior to traditional EPQ model solutions, but also result in significantly smaller cost flow variability.

\section{REFERENCES}

Arreola-Risa, A. and G.A. DeCroix, 1998. DeCroix, Inventory management under random supply disruptions and partial backorders. Naval Res. Logistics, $\quad$ 45: 687-703. http://faculty.fuqua.duke.edu/ decroix/bio/ArreolaRisa-DeCroix-NRL-98.pdf

Berk, E. and A. Arreola-Risa, 1994. Note on Future Supply Uncertainty in EOQ models. Naval Res. Logistics, 41: 129-132. DOI: 10.1002/15206750(199402)41:1<129::AIDNAV3220410109>3.0.CO;2-M

Cachon, G.P. and M. Fisher, 2000. Supply chain inventory management and the value of shared information. Manage. Sci., 46: 1032-1048. DOI: 10.1287/mnsc.46.8.1032.12029

Chang, C.C., 2002. The economical quantity pattern of the unreliable production system and the defect and the repetition process consideration. Master Dissertation, Industrial Management Department, National Cheng Kung University.

Chen, Y.M., C.T. Lin, C.Y. Lo and C.F. Wu, 2006. Establish an adaptive $(\mathrm{s}, \mathrm{S})$ production system under imperfect production conditions by fuzzy analytic hierarchy process. Proceedings of the 2006 IEEE International Conference on Fuzzy Systems, July 15, Vancouver, BC, Canada, pp: 962-968. DOI: 10.1109/FUZZY.2006.1681827

Chopra, S., G. Reinhardt and U. Mohan, 2005. The importance of decoupling Recurrent and disruption risks in a supply chain. Working study, Northwestern University, Evanston, Illinois.

Chopra, S., G. Reinhardt and U. Mohan, 2007. The importance of decoupling recurrent and disruption risks in a supply chain. Naval Res. Logistics, 54: 544-555. DOI: 10.1002/nav.20228

Fernandez-Ranada, M., X. Gurrola-Gal and E. LopezTello, 1999. 3C: A Proven Alternative to MRPII for Optimizing Supply Chain Performance. 1st Edn., CRC Press, Delray Beach, FL., ISBN-10: 1574442716, pp: 272.

Gupta, D., 1996. The (Q,r) inventory system with an unreliable supplier. INFOR 34: 59-76. http://direct.bl.uk/bld/PlaceOrder.do?UIN=010709 $349 \&$ ETOC $=\mathrm{RN} \&$ from $=$ searchengine

Holmstrom, F.K., K. Framling, R. Kaipia and F. Saranen, 2002. Collaborative planning forecasting and replenishment. Supply Chain Manage.: Int. J., 7: 136-145. DOI: 10.1108/13598540210436595

Huang, Y.N., 2004. A study on the spare part stock management-the application of $3 \mathrm{C}$ and CPFR. Thesis for Master Degree, Graduate School of Industrial Management, National Taiwan University of Sciences and Technology.

Kimemia, J. and S.B. Gershwin, 1983. An algorithm for the computer control of a flexible manufacturing system. IIE Trans., 15: 353-362. DOI: 10.1080/05695558308974659

Kumar, S. and D. Meade, 2002. Has MRP run its course? A review of contemporary development in planning systems. Indus. Manage. Data Syst., 102: 453-462. DOI: $10.1108 / 02635570210445880$

Lee, H., 2002. Aligning supply chain strategies with product uncertainties. California Manage. Rev., 44: 105-119.

http://direct.bl.uk/bld/PlaceOrder.do?UIN=115006 $101 \&$ ETOC $=$ RN\& from $=$ searchengine

Lee, H.L. and C.A. Yano, 1988. Production control in multistage systems with variable yield losses. Operat. $\quad$ Res., $\quad 36$ : 269-278. http://www.jstor.org/pss/171281

Lee, H.L., 1992. Lot sizing to reduce capacity utilization in a production process with defective items, process corrections and rework. Manage. Sci., $\quad 38$ : 1314-1328. http://www.jstor.org/pss/2632636

Lewis, B.M. A.L. Erera and C.C. White, 2005. An inventory control model with possible border disruptions. Working study, Georgia Institute of Technology, Atlanta. http://www2.isye.gatech.edu/people/faculty/Alan_ Erera/pubs/LewisEreraWhite2005.pdf

Lin, C.-T. and Y.-M. Chen, 2009. Hedging strategic flexibility in the distribution optimization problem. Omega, 37: 826-837. DOI: 10.1016/J.OMEGA.2008.07.008 
Liu, B. and J. Cao, 1997. Production control of an unreliable manufacturing system under the assumption of no backlog. Math. Methods Operat. Res., 46: 103-117. DOI: 10.1007/BF01199465

Liu, J.J. and P. Yang, 1996. Optimal lot-sizing in an imperfect production system with homogeneous reworkable jobs. Eur. J. Operat. Res., 91: 517-527. DOI: 10.1016/0377-2217(94)00339-4

Meyer, R.R., M.H. Rothkopf and S.A. Smith, 1979. Reliability and inventory in a production-storage system. Manage. Sci., 25: 799-807. http://www.jstor.org/pss/2630316

Olugu, E.U. and K.Y. Wong, 2009. Supply Chain performance evaluation: Trends and challenges. Am. J. Eng. Applied Sci., 2: 202-211. DOI: 10.3844/ajeassp.2009.202.211

Parlar, M. and D. Berkin, 1991. Future supply uncertainty in EOQ models. Naval Res. Logistics, 38: $\quad 107-121$ DOI: $10.1002 / 1520-$ 6750(199102)38:1<107::AIDNAV3220380110>3.0.CO;2-4

Parlar, M., 1997. Continuous-review inventory problem with random supply interruptions. Eur. J. Operat. Res., 99: 366-385. DOI: 10.1016/S03772217(96)00165-8
Ross, S.M., 1997. Introduction to Probability Models. 6th Edn., Academic Press, San Diego, CA, USA., ISBN-10: 0125984707, pp: 669.

Scheffe, H., 1947. A useful convergence theorem for probability distributions. Ann. Math. Statist, 18: 434-458. http://www.jstor.org/pss/2235739

Tomlin, B.T. and L.V. Snyder, 2006. Inventory Management with Advanced Warning of Disruptions. Working study, Lehigh University, Bethlehem, Pennsylvania. http://www.kellogg.northwestern.edu/meds/deptinf o/msom2005/papers/Snyder.pdf

Tomlin, B.T., 2006. On the value of mitigation and contingency strategies for managing supply chain disruption risks. Manage. Sci., 52: 639-657. DOI: 10.1287/mnsc. 1060.0515

Usman, A. and N.M. Kontagora, 2010. Statistical process control on production: A case study of some basic chemicals used in pure water production. Pak. J. Nutr., 9: 387-391. http://xa.yimg.com/kq/groups/24709041/13779011 50/name/Statistical+process+control+on+productio $\mathrm{n}+\mathrm{A}+$ case + study+of + some+basic + chemicals+used + in+pure+water+production.pdf

Yano, C.A. and H.A. Lee, 1995. Lot sizing with random yield: A review. Operat. Res., 43: 311-334. DOI: $10.1287 /$ opre.43.2.311 